\title{
Research on the Trust Mechanism of Individual Consumers in Rural Financial Markets Based on the Dynamic CGE Model
}

\author{
Fang Lin ${ }^{1}{ }^{1}$ and Wenxiang Chen (D) $^{2}$ \\ ${ }^{1}$ School of Economics and Management, Fujian Vocational College of Agriculture, Fuzhou 350002, China \\ ${ }^{2}$ State-Owned Assets Management Office, Fujian Agriculture and Forestry University, Fuzhou 350002, China \\ Correspondence should be addressed to Wenxiang Chen; chenwenxiang@fafu.edu.cn
}

Received 16 October 2021; Revised 9 November 2021; Accepted 13 November 2021; Published 4 January 2022

Academic Editor: Hai Dong

Copyright (c) 2022 Fang Lin and Wenxiang Chen. This is an open access article distributed under the Creative Commons Attribution License, which permits unrestricted use, distribution, and reproduction in any medium, provided the original work is properly cited.

\begin{abstract}
In order to obtain the complete equilibrium state of rural financial market and ensure the stable development of rural financial consumer market, this paper introduces CGE model and analyzes the dynamic trust mechanism of individual consumers in rural financial market. In this paper, the single variable evolutionary fuzzy clustering algorithm is used to analyze the orthogonal eigenvector solutions of individual consumers; the big data of individual consumers under the mode of perceived trust is automatically clustered, so as to obtain the fuzzy analogy function of individual consumers in the rural financial market; and finally the prediction value of consumer trust is obtained. The results show that trust, customer satisfaction, and service quality are positively correlated. Under the same sample expectation constraints, the dynamic CGE model is more robust, and the individual consumer trust mechanism of rural financial market in the study area has higher advantages.
\end{abstract}

\section{Introduction}

Since the late 1990s, in order to meet the challenges of domestic and foreign banking industry, commercial banks, especially the Agricultural Bank of China, have significantly accelerated the pace of building modern commercial banks. The operation has obviously turned to the direction of commercialization, a large number of township institutions have been merged, and loans tend to be large customer groups [1]. Not only make it appear fault in rural financial services, but also make a large number of rural funds have turned to the city, so that the supporting role of commercial finance on rural economy is weakening. In fact, the rural financial field is also a promising field. The rural financial market should not become a wasteland of commercial finance. Although China has been an agricultural policy bank for more than ten years, the current agricultural development bank has a single source of funds and a heavy burden of nonperforming assets. Rural financial consumption refers to the behavior that rural residents purchase financial products provided by financial institutions in order to meet their own consumption needs and enjoy financial services. The construction and improvement of rural financial consumption market are closely related to the overall development pattern of China's financial industry [2]. Building a stable rural financial consumer market is of great practical significance for expanding the domestic demand and promoting the stable development of rural economic and financial market. Based on the stable development of the market, consumer trust plays an important role in the rural financial consumption market. From the perspective of relationship marketing, trust plays an important role in strengthening relationships. Keeping trust with consumers is the most effective way for enterprises to carry out relationship marketing. In the case of uncertainty, high risk, and lack of contract and guarantee, the establishment of consumer trust has far-reaching significance for enterprises, which helps to establish stable customer relationship and maintain market share [3].

CGE model is essentially a micro model of multiple sectors and multiple markets; it also contains a lot of macroeconomic content. CGE model can make feedback adjustment and spontaneous decision by setting the optimal 
decision of decision-makers, so it has obvious advantages over other research methods in analyzing the effect of policy changes. Using CGE model to analyze the trust mechanism of individual consumers in rural financial market dynamically, we can classify and refine the production sector or individual consumption factors, link the resources and environment variables with relevant departments, and obtain the production function or consumption function without changing the basic assumptions and structure of the model. This paper analyzes the formation and evolution of individual consumer trust mechanism in rural financial market and puts forward some suggestions for its development.

CGE is a model based on general equilibrium theory, which can calculate the equilibrium solution, involving three aspects of interpretation.

Computability means taking the real economic data as the input and calculating the equilibrium solution.

Generality means multiple industries and multiple subjects, such as government, family, industry, and trading partners; general behavior equation, utility maximization, and profit maximization.

Equilibrium means demand $=$ supply. Through price changes, the product and factor markets can be cleared.

Because of the above characteristics of CGE, this method can be easily applied to research on the trust mechanism of individual consumers in rural financial. According to the CGE method, we analyze the constraints of the rural financial consumer market and then introduce the trust mechanism of individual consumers in the financial market, extending the CGE model. Besides, we analyze the relationship between rural customers' perception of financial service quality, customer satisfaction, and customer trust and set the variables and conditions of the CGE extended model to judge whether the rural financial consumer market is in a stable development state. This paper determines the credit risk evaluation index, introduces the improved analytic hierarchy process, evaluates the credit risk of individual consumers in rural financial market, determines the advantages of the trust mechanism of individual consumers in rural financial market, and makes a dynamic analysis of the trust mechanism of individual consumers in rural financial market.

The contributions of this paper can be described as follows:

(1) In this paper, the single variable evolutionary fuzzy clustering algorithm is used to analyze the orthogonal eigenvector solutions of individual consumers; the big data of individual consumers under the mode of perceived trust is automatically clustered, so as to obtain the fuzzy analogy function of individual consumers in the rural financial market; and finally the prediction value of consumer trust is obtained.

(2) This paper analyzes the constraints of the rural financial consumer market, introduces the trust mechanism of individual consumers in the financial market, extends the CGE model, and analyzes the relationship between rural customers' perception of financial service quality, customer satisfaction, and customer trust.

(3) This paper determines the credit risk evaluation index, introduces the improved analytic hierarchy process, evaluates the credit risk of individual consumers in rural financial market, and determines the advantages of the trust mechanism of individual consumers in rural financial market.

The remainder of this paper is organized as follows. Section 2 introduces the perceived trust model of individual consumers in rural financial market. Section 3 discusses the dynamic CGE model of individual consumer trust mechanism in rural financial market. Section 4 discusses experiment and analysis. Section 5 presents the conclusions of the study.

\section{The Perceived Trust Model of Individual Consumers in Rural Financial Market}

The steady improvement of the overall income level of rural residents, the continuous increase of disposable financial consumption income, and the continuous updating of consumption concept set higher requirements for the diversification of rural financial consumption products and financial services [4]. However, the products in the market are uneven, which requires consumers to have perception and trust in the rural financial market, so it is necessary to improve the quality of products. In this paper, single variable evolutionary fuzzy clustering algorithm is used to analyze the orthogonal eigen vector solutions of individual consumers. Assuming a single component of individual consumers' perceived trust $\varepsilon_{k}$, the individual consumer feature $x\left(t_{n+1}\right)$ decomposition model is obtained:

$$
\begin{aligned}
V V^{T} & =I_{M}, \\
\sum & =\operatorname{diag}\left(\sigma_{1}, \sigma_{2}, \ldots, \sigma_{m}\right) \in R^{m \times m}, \\
V V^{T} & =I_{M}, \\
\sum & =\operatorname{diag}\left(\sigma_{1}, \sigma_{2}, \ldots, \sigma_{m}\right) \in R^{m \times m},
\end{aligned}
$$

where $R^{T} R$ represents the continuous statistical characteristic quantity of the personal consumer information sampling sequence $R^{m \times m}$. Since there is a surplus probability in the statistical process, the size of the distribution characteristic value of the personal consumer is ranked:

$$
\sigma_{1}>\sigma_{2}>\sigma_{3}>\cdots>\sigma_{s+1}>\sigma_{m} .
$$

Under the evolutionary game, the new characteristic sequence of individual consumers in rural financial market is as follows:

$$
\begin{aligned}
X_{m+1}(m)= & X_{k+1}(m) \\
& \pm \sqrt{\left(d_{m}(0) e^{\lambda_{1}}+\right)^{2}-\sum_{i=1}^{m-1}\left[X_{m+1}(i)-X_{k+1}(i)\right]^{2}} .
\end{aligned}
$$


Under the condition of local stability analysis, the quantitative prediction value of individual consumers is obtained as follows:

$$
x\left(t_{n+1}\right)=X_{m+1}(m) .
$$

The expected value $R^{T} R$ and standard deviation $\varepsilon_{k}$ in the Gaussian self-similar process of individual consumer sequence are set as $R^{T} R=0, D_{0}=1,=1$, and $k=1,2, \ldots, n-1$, respectively. After reconstructing the phase space of the evolution data sequence of individual consumer, the fuzzy clustering method is used to automatically cluster the big data of individual consumer under the perceptual trust mode, and a group of new time series that replace individual consumer are mined, The results are as follows:

$$
\begin{aligned}
D_{k} & =\frac{D_{k-1}-N_{k-1}^{2}}{D_{k-1}}, \\
\phi_{k k} & =\frac{N_{k}}{D_{k}}, \\
\phi_{k j} & =\phi_{k-1, j}-\phi_{k k} \cdot \phi_{k-1, k-j} .
\end{aligned}
$$

In the Gaussian distribution $\mathrm{N}(0,1)$ of individual consumers, an initial value of $x_{0}$ is generated. Based on the initial value, the trust perception is iteratively calculated. Suppose that the discrete characteristic component of individual consumers' demand information in the perceived trust mode is $s_{i}=\left(x_{i}, x_{i+\tau}, \ldots, x_{i+(m-1) \tau}\right)^{T}$, and the above formula is a short-term discrete information distribution set, which is embedded in the embedded space of individual consumers in the rural financial market. The distribution function of the state set of individual consumers in the rural financial market under the mode of perceived trust is obtained as follows:

$$
\frac{\mathrm{d} \mathbf{z}(t)}{\mathrm{d} t}=F(\mathbf{z}) .
$$

In order to ensure that the effective probability density of individual consumers in rural financial market is high, the appropriate $s_{i}=\left(x_{i}, x_{i+\tau}, \ldots, x_{i+(m-1) \tau}\right)^{T}$ and $s_{i}=\left(x_{i}, x_{i+\tau}, \ldots, x_{i+(m-1) \tau}\right)^{T}$ are selected according to the above formula:

$$
R_{1}=\left\{X_{1}, X_{2}, X_{3}, \ldots, X_{d}\right\}^{T} .
$$

Through multiple comparison analysis, the correlation function of individual consumers in rural financial market is obtained as follows:

$$
R_{1}^{T} R_{1}=\left\{X_{1}, X_{2}, \ldots, X_{m}\right\}\left\{X_{1}, X_{2}, \ldots, X_{m}\right\}^{T} .
$$

A pre-estimator is set to calculate the best decomposition value $V_{1}^{T}$ of individual consumers in rural financial market:

$$
R_{1}{ }^{T} R_{1}=V_{1} \sum V_{1}^{T} \text {. }
$$

Assuming that $\mathbf{x}_{j}$ is an $\mathbf{x}_{i}$ nearest neighbor function, this paper uses earnings management method to make fuzzy prediction of individual consumers from $L+1$ to $2 L$ dimensions. In this process, $X_{m}$ in the phase space is taken as the central point, and the fuzzy analogy of individual consumers in the rural financial market under the mode of perceived trust is as follows:

$$
\begin{aligned}
R_{2}^{T} R_{2} & =V_{2} \sum_{2} V_{2}^{T}, \\
R_{2} & =\left\{X_{d+1}, X_{d+2}, \ldots X_{d+m}\right\}^{T}, \\
R_{2}^{T} R_{2} & =\left\{X_{d+1}, X_{d+2}, \ldots X_{d+m}\right\}\left\{X_{d+1}, X_{d+2}, \ldots X_{d+m}\right\}^{T} .
\end{aligned}
$$

In the formula, the wide area characteristic component of individual consumers in rural financial market is as follows:

$$
V=\left[V_{1}, V_{2}, \ldots, V_{m}\right] \in R^{m \times m} .
$$

Through univariate analysis of variance, according to the evolution characteristics of predicted values $X_{m}$ and $X_{k}$, the predicted values of consumer trust are $X_{m+1}$ and $X_{k+1}$.

\section{Dynamic CGE Model of Individual Consumer Trust Mechanism in Rural Financial Market}

3.1. Dynamic Analysis of Trust Mechanism of Individual Consumers. The traditional CGE model is based on the pure economic system, so SAM accounting framework, as the database of CGE model, only describes the pure economic aspects of production, consumption, and other activities, excluding the resource and environmental losses caused by economic activities and corresponding protection activities [5]. In fact, if we make proper use of resources and environment in economic activities and take timely measures to protect rural resources and control pollution, the interaction between resources, economy, and environment will be in a virtuous circle. Therefore, a completely balanced state is the stable development of rural financial consumption market. However, there are still many restrictive factors in the rural financial consumption market, like the following:

(1) It is difficult for low coverage of rural financial services and relatively single financial products to meet the diversified needs of rural consumer groups for financial services. First, the service coverage of financial institutions is relatively narrow. Rural financial service coverage refers to the level and degree of financial services such as deposit, loan, settlement, and financial management provided by financial institutions for enterprises and farmers in rural areas. It is the main quantitative index to evaluate the status of rural financial services. Due to the fact that quite a number of banking financial institutions have realized the strategic transfer from villages and towns to large- and medium-sized cities, the underdeveloped rural areas have become the areas with extremely weak financial strength. Second, there are few kinds of suitable financial service products. The design of financial consumer products for rural residents by rural financial institutions is far behind 
the current needs. Relying on the villages and towns, the financial services of financial institutions in the vast rural areas still stay at the level of traditional business such as deposit, means of production loan, and general settlement, which makes the financial supply and farmers' demand unable to smoothly connect, thus restricting the normal start of rural financial consumer market. Third, the appropriate financial products are not yet mature. Financial consumer products lack proper standards and mislead financial consumers to buy financial products from time to time.

(2) The low efficiency and fairness of rural financial services cannot meet the diversified needs of rural consumer groups. One is the restriction of loan approval authority [6]. A considerable number of rural financial institutions lack sufficient approval authority due to the collection of loan authority, which makes it more difficult for rural financial consumers to raise funds, thus missing the best opportunity for investment or production. The second is the restriction of financial resources allocation. Quite a number of banking financial institutions lack sufficient attention to all kinds of loans in rural areas for their own economic interests and credit risk prevention $[7,8]$. The third is the restriction of payment and settlement system. Due to the backward construction of rural financial payment and settlement service system, the low level of rural financial services, and the lack of financial consumer products and financial publicity, farmers have less knowledge and use of modern financial knowledge and investment and financial products, and it is difficult for the relatively weak rural financial consumer groups to enjoy modern financial services [9].

Therefore, in order to highlight the coverage of rural financial services and the role of efficiency and fairness of rural financial services in farmers' production activities, we introduce the trust mechanism of individual consumers in the financial market and expand the CGE model; that is, besides land, capital, and labor, we introduce the virtual element of "individual consumer trust," as shown in Figure 1.

In the multilayer nested structure shown in Figure 1, the first level first synthesizes the intermediate input and initial factor input (added value) of nonindividual consumer trust into the total output of the department in the form of CES function. In the second level, the intermediate input of nonindividual consumer trust is decomposed into various intermediate inputs according to Leontief structure; that is, there is no substitutability between inputs, and the added value of the same level is decomposed into labor force and generalized capital (including capital, land, individual consumer trust, and natural endowment) according to CES structure. In the third level, labor force is further decomposed into agricultural labor force, industrial workers, and technicians with CES structure, and generalized capital is further decomposed into individual consumer trust and capital land endowment with CES structure. In the fourth level, the individual consumer trust is divided into the input of various individual consumer trust products. The model assumes that there is a certain substitution possibility between different individual consumer trust inputs (such as the substitution of coal, oil, and natural gas), so all kinds of individual consumer trust inputs synthesize individual consumer trust with CES structure. At the same time, capital land endowment is decomposed into capital land and natural endowment. As a necessary and irreplaceable input factor, natural endowment enters the equation in a fixed proportion and is combined with capital land in the form of Leontief function. Finally, capital land is decomposed into capital and land in CES structure (this study is from the perspective of individual consumers and does not involve the issue of energy output).

3.2. Variable Setting and Reduction Conditions of CGE Extended Model. Customers with trust can bring profit growth. With the successive establishment of rural banks and the increasing number of rural financial outlets of banks and credit enterprises, the competition in rural financial market will be fiercer and fiercer [10-12]. Therefore, how to improve the quality of rural financial services, promote the trust of rural customers, and retain customers is an important issue for financial enterprises. Therefore, it is necessary to start from the relationship between whether the customer has trust, customer satisfaction, and service quality and establish the relationship model of rural customers' perception of financial service quality, customer satisfaction, and customer trust according to the existing theoretical research results and relevant research experience, as shown in Figure 2.

The income of rural residents mainly comes from the factor income of labor and capital, as well as the transfer payment of government, enterprises, and foreign countries. After paying personal income tax, residents use disposable income for saving and consumption, which is reflected in commodity market equilibrium, factor market equilibrium, government budget equilibrium, balance of international payments, and balance of savings and investment, mainly describing nominal and real GDP and social welfare. In the dynamic module, capital accumulation, population, and labor force changes are introduced to make the model dynamic. From the macro point of view, in order to make the model achieve a stable and balanced growth path [13, 14], this paper sets the growth rate of the main exogenous variables to be consistent with the population growth rate

$$
H_{K}=\frac{\left(1-\operatorname{dep}_{t}\right) \cdot K \cdot K_{a}+\operatorname{ENTSAV}_{t}}{\sum_{t} K^{t+1} \cdot W^{\text {zeta }} \cdot K^{t}},
$$

where $K^{t+1}$ is the capital supply in $t+1$ period, $\operatorname{dep}_{t}$ is the composite investment price $K_{a}$ in $t$ period, $w_{k} t$ is the capital price in $t$ period, zeta is the elastic parameter of investment distribution, ENTSAV ${ }_{t}$ is the household savings in $t$ period, and $K^{t}$ is the labor supply in $t$ period.

Because the approximate conditions of the model are that the variable is stable and balanced, it is dynamic. If the 


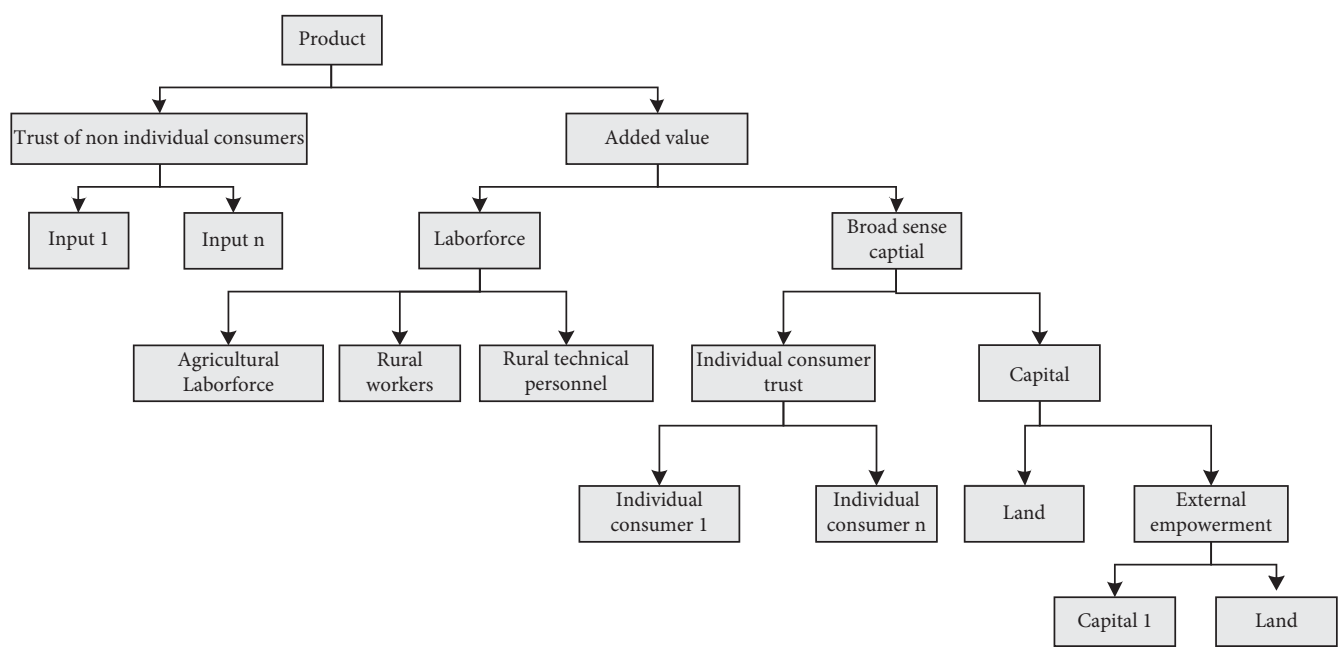

FIgURE 1: CGE extended structure.

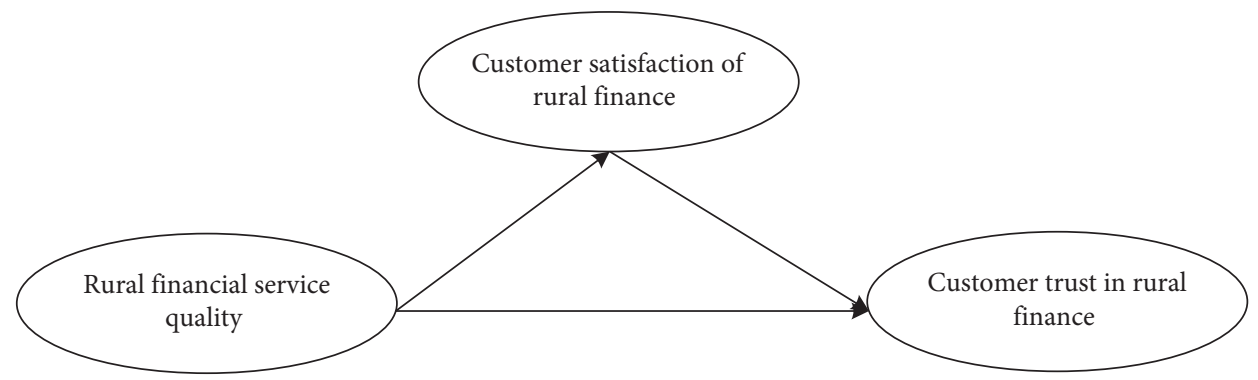

FIgURE 2: The relationship between rural customers' perception of financial service quality, customer satisfaction, and customer trust.

model has only one solution, it can be judged that the rural financial consumption market in the region is developing steadily.

\subsection{Credit Risk Assessment of Individual Consumers in Rural} Financial Market. There are two basic relationships in human economic activities: the relationship between man and nature and the relationship between man and man. There are both cooperation and conflict between people. In order to effectively resolve conflicts, promote cooperation, and improve the welfare level of social members, human beings have invented various systems to regulate their own economic behavior in the long-term evolutionary game. In any transaction, if the buyer does not trust the quality and quality of the products provided by the seller, or the seller does not trust the buyer's means of payment, there is no way to conduct the transaction. In this sense, without trust, there will be no transaction and no market [15]. However, trust must be mutual. Therefore, after determining the degree of trust of individual consumers in the market, it is necessary to determine the degree of trust of the market subject, that is, the enterprise to individual consumers, that is, to determine the credit risk of consumers.

The enterprise is to determine the credit risk evaluation index as the premise to evaluate the credit risk of customers. Credit risk index can comprehensively evaluate the comprehensive level of customers and credit management.
Customer credit risk assessment indicators follow the principles of comprehensiveness, scientificity, practicability, and operability and the combination of quantitative and qualitative. It mainly investigates customer credit status from the aspects of trading environment, mortgage, ethics, capital, and rural financial market capabilities The specific level is shown in Table 1.

In Table 1, regarding environment, the law of social and economic development and the special changing market transactions in a certain region affect the solvency of customers, mainly selecting the macro environment and medium environment that affect enterprises. With respect to mortgage, customers use their assets as guarantee for repayment, and the main indicators are mortgage and guarantee under customer market transactions. As for morality, the possibility of payment commitment to market transaction is evaluated according to customer's previous credit record. Because of the special needs of enterprises, the index is directly selected by obtaining the information resources of customer market transactions. Concerning capital, the financial status of customers is analyzed according to the financial statements of enterprises, which is the basic guarantee for the repayment ability of customers' market transactions. In respect of ability, the customer's market transaction payment ability is judged according to the customer's business status and asset status. The main selected indicators are financial indicators reflecting the profitability and solvency of enterprises. 
TABLE 1: Credit risk assessment index system.

\begin{tabular}{lcc}
\hline $\begin{array}{l}\text { Target } \\
\text { layer }\end{array}$ & Criterion layer & Index layer \\
\hline & $\begin{array}{c}\text { Environment } \\
\text { Mortgage } \\
\text { Credit } \\
\text { risks }\end{array}$ & $\begin{array}{c}\text { Enterprise development prospects, technical factors, social and cultural factors, economic factors, } \\
\text { industry nature, political factors, legal factors, and other factors. } \\
\text { Customer mortgage. }\end{array}$ \\
& $\begin{array}{c}\text { Capacity } \\
\text { Character }\end{array}$ & $\begin{array}{c}\text { Public information, litigation for breach of contract, execution and scheduling, illegal transactions, on- } \\
\text { time repayment rate of loans, cumulative arrears ratio, average payment days, and arrears ratio. }\end{array}$ \\
\hline
\end{tabular}

Taking the credit risk in Table 1 as the judgment index, this paper introduces the improved AHP method (analytic hierarchy process) to evaluate the credit risk of individual consumers in rural financial market, that is, customers. The algorithm uses the concept of optimal transfer matrix to improve AHP, so that it can naturally meet the consistency requirements and directly calculate the weight value, that is, the credit risk value. The specific steps are as follows:

(a) Set up credit risk evaluation index system based on market transaction. According to the customer credit evaluation index system, set up the evaluation index set; refer to Table 1.

(b) The judgment matrix is established. After establishing the matrix according to the credit risk evaluation index system, the weight of each level index in the customer credit risk evaluation index system is determined by AHP. By comparing the two elements, the importance of the elements in the hierarchy relative to a certain factor in the upper level is clarified, and the judgment matrix of comparing the two factors is constructed. The judgment matrix of two factors for a certain criterion is calculated as follows:

$$
\begin{aligned}
B & =\left(b_{i j}\right)_{\min }, \\
b_{i j} & =\frac{b_{j k}}{b_{j k}}, \quad i, j, k=1,2 \ldots, n,
\end{aligned}
$$

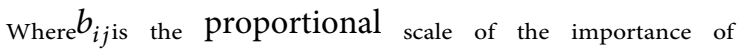

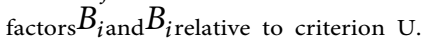

C. Based on the improved AHP method, calculate the weight of each level evaluation index. After using the improved AHP method to calculate the index weight, there is no need to do consistency test. Firstly, the established judgment matrix is transformed to obtain the quasi-optimal matrix $B^{*}$ (as shown in Figure 3 ). The square root method is used to solve the eigenvector of the modified $B^{*}$. Multiply the elements of the judgment moment by lines to get the following formula:

$$
N_{i}=\prod_{j=1}^{n} b_{i j}, \quad i=1,2,3 \ldots n .
$$

Open the n-th root of the product to calculate $P_{i}=N_{i}{ }^{1 / n}$. Normalize the root vector $P=\left[P_{1}, P_{2}, \ldots, P_{n}\right]^{Q}$ to get the ranking weight vector $P$.

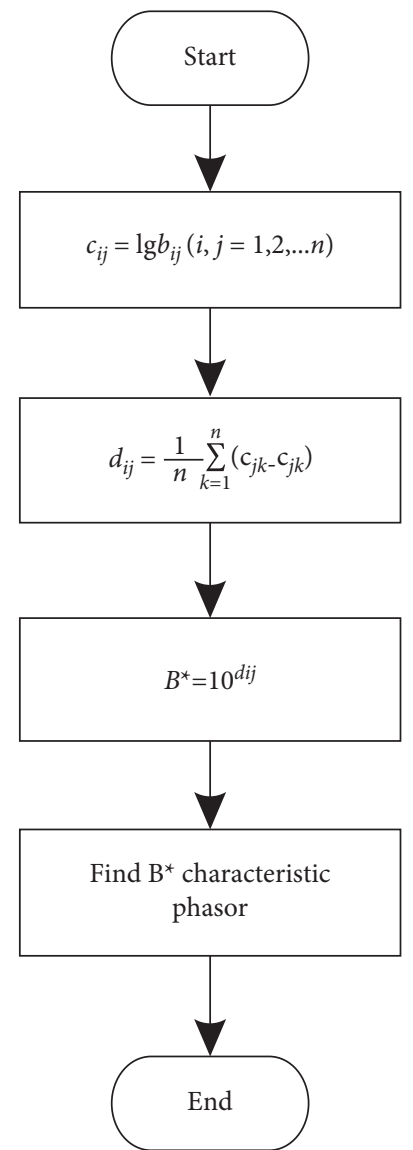

FIGURE 3: Credit risk assessment process of individual consumers in rural financial market.

Credit risk assessment process of individual consumers in rural financial market is shown in Figure 3.

$$
p=\frac{P_{i}}{\sum_{j=1}^{n} P_{j}}
$$

At this time, $P$ means the credit risk value of individual consumers in rural financial market. The higher the risk value is, the lower the trust degree of enterprises in individual consumers is. The abovementioned CGE expansion model has many variables, and the trust mechanism of individual consumers in the rural financial market is limited. On the contrary, the trust mechanism of individual consumers in the rural financial market is more superior. 


\section{Experimental Analysis}

4.1. Data Sources and Basic Information. This study takes the customers of rural commercial banks, credit cooperatives, some rural banks, and other financial service institutions in a province as the survey objects. The descriptive statistical data obtained show that the basic characteristics of the survey objects, such as age, sex ratio, education level, and family income, are consistent with the reality, with a normal distribution, and their Cronbach's alpha coefficient is $53.53 \%$. The rotation factor load of each index item exceeded 0.7 , and the scale had good validity $(P \leq 0.001)$. The Pearson correlation coefficients of the three dimensions were lower than 0.5 , and there was no serious collinearity between the dependent variable and the independent variable.

Based on this, this paper uses SPSS17.0 software to test the relationship between trust, customer satisfaction, and service quality. The test results are shown in Table 2 .

Table 2 shows that from the $F$ value of regression equation, they all reached the extremely significant degree $(P<0.001)$. In rural financial services, customer's attitude satisfaction is significantly positively affected by rural financial service's tangibility, responsiveness, certainty, and empathy; result satisfaction is significantly positively affected by rural financial service's tangibility and responsiveness; process satisfaction is significantly positively affected by rural financial service's tangibility, reliability, and responsiveness. Environmental satisfaction is significantly positively affected by the tangibility and certainty of rural financial services, while capability satisfaction is significantly positively affected by the tangibility, responsiveness, and certainty of rural financial services, Empathy has a positive impact on attitude satisfaction, which makes customers have trust.

Using the descriptive statistical analysis method in Table 1, this paper makes a linear analysis of individual consumer trust in rural financial market under the mode of perceived trust.

Using $p_{i}$, one of the above samples belongs to the possibility of available $C_{i}$, and $s_{i} / s$ is used to estimate it. Suppose that the set $v$ with attribute $A$ and $v$ different values can be equally divided into subsets $A$ by attribute $A$, in which $S_{j}$ includes such part of the samples in $S$, and all of them have the same value of $a_{j}$ on $A$. Then, when $A$ is selected as the test attribute, some subsets will correspond to the node branches of set $S$. If $s_{i j}$ is the specific number of samples of class $C_{i}$ in subset $s_{j}$, then according to the expected value information formula divided into subsets by $A$, there is

$$
E(A)=\frac{\sum\left(s_{1 j}+\cdots+s_{m j}\right) * I\left(s_{1 j}+\cdots+s_{m j}\right)}{s} .
$$

Thus, under different sample models from 2011 to 2020 , with the same sample expectation as the constraint, the analysis results of individual consumer trust in rural financial market are obtained, as shown in Table 3 .

According to the analysis results of trust bias distribution and descriptive comparison in Table 1, the above experimental results are available, and the dynamic CGE model of individual consumer trust mechanism in rural financial market is more robust.

\subsection{Discussion and Suggestions}

(1) Most dimensions of rural financial service customer satisfaction are positively correlated with customer trust. Specifically, the degree of customer's attitude trust in rural financial services is mainly positively affected by attitude satisfaction and result satisfaction, and the degree of behavior trust is mainly positively affected by environment satisfaction and ability satisfaction. This shows that the more satisfied the rural customers are with the service attitude of financial services, the more consistent the service result is with the customer's expectation, and the stronger the customer's preference for the service provider is. The more satisfied the customers are with the service environment and serviceability of financial institutions, the higher the degree of trust is, and the more willing the customers are to choose the products and services they want to build again. From the perspective of the effect of rural financial service quality on customer loyalty, rural customers' attitude trust is positively affected by the tangible benefits and responsiveness of financial services, and their behavior trust is mainly affected by reliability and certainty, while rural financial customers' cognitive trust is not significantly affected by service quality.

(2) There is a positive correlation between financial service quality and customer trust. Specifically, the impact of customer attitude loyalty is mainly customers' perception of financial service tangibility and responsiveness, and the impact of behavior loyalty is mainly customers' perception of financial service reliability. This shows that the better the hardware facilities of rural financial enterprises are, the higher the service efficiency is, and the easier the customers will have a good reputation for the financial service providers. The more stable the financial products and reliable the services provided by rural financial enterprises are, the more customers tend to choose the enterprise repeatedly and recommend it to others.

The steady development of the rural financial consumer market is inseparable from the service and support of the rural finance, and also inseparable from the protection of financial consumers' rights and interests by government functional departments. The protection of financial consumers' rights and interests highlights the cultivation and perfection of the rural financial consumer market, and the development of the rural financial consumer market can promote the prosperity and stability of the rural financial industry, which have a positive impact on each other.

\subsubsection{Market}

(1) We will improve the rural financial service system and expand the coverage of rural financial services. Based on the existing organizational framework of rural financial institutions, we should speed up the construction of a modern rural financial service 
TABLE 2: Test results of the relationship between trust, customer satisfaction, and service quality.

\begin{tabular}{|c|c|c|c|c|c|}
\hline Variable & $\begin{array}{l}\text { The results are } \\
\text { satisfactory }\end{array}$ & $\begin{array}{c}\text { Process } \\
\text { satisfaction }\end{array}$ & $\begin{array}{l}\text { Satisfied with the } \\
\text { environment }\end{array}$ & $\begin{array}{l}\text { Ability } \\
\text { satisfaction }\end{array}$ & $\begin{array}{c}\text { Satisfied with } \\
\text { attitude }\end{array}$ \\
\hline Gender & 0.048 & 0.123 & --0.007 & 0.013 & 0.022 \\
\hline Age & -0.001 & -0.017 & $-0.017^{* * * *}$ & 0.045 & 0.017 \\
\hline Degree of education & -0.07 & -0.069 & 0.069 & 0.069 & 0.069 \\
\hline Income & 0.046 & 0.046 & 0.046 & 0.046 & 0.046 \\
\hline $\begin{array}{l}\text { The tangibility of financial } \\
\text { services }\end{array}$ & $0.289^{* * * *}$ & $-0.335^{* * * *}$ & $-0.135^{* *}$ & $-0.250^{* * * *}$ & $-0.205^{* * * *}$ \\
\hline $\begin{array}{l}\text { Reliability of financial } \\
\text { services }\end{array}$ & 0.179 & 0.07 & $0.217^{* * * *}$ & --0.07 & --0.07 \\
\hline $\begin{array}{l}\text { Responsiveness of financial } \\
\text { services }\end{array}$ & $0.117^{* * * *}$ & 0.017 & $0.117^{* * *}$ & -0.017 & -0.017 \\
\hline Certainty of financial services & $0.169^{* * *}$ & -0.069 & 0.069 & 0.059 & 0.049 \\
\hline Empathy of financial services & $27.152^{* * * *}$ & $16.045^{* * * *}$ & $19.486^{* * *}$ & $14.546^{* * * *}$ & $13.146^{* * * *}$ \\
\hline$F$ & 0.635 & 0.525 & 0.515 & 0.545 & 0.485 \\
\hline$R$ & 0.357 & --0.257 & --0.217 & --0.227 & --0.210 \\
\hline
\end{tabular}

"represents $P<0.05,{ }^{* *}$ represents $P<0.01,{ }^{* *}$ represents $P<0.005$, and ${ }^{* *}$ represents $P<0.001$.

TABLE 3: Analysis results of individual consumer trust in rural financial market.

\begin{tabular}{lccc}
\hline Year & $2011-2015$ & $2016-2018$ & $2019-2020$ \\
\hline $2011-2015$ & 1 & & \\
$2016-2018$ & 0.0455 & 1 & \\
$2019-2020$ & $0.0452^{* *}$ & $0.0523^{*}$ & 1 \\
\hline
\end{tabular}

${ }^{*}$ means significant at the level of 0.05 .

system with sound functions, reasonable layout, orderly competition, and efficient services. First, further improve the rural financial service system, clear positioning, strengthen supervision, and encourage the development of various ownership financial organizations. We should continue to cultivate and develop new rural financial institutions such as rural banks, enhance the ability of sustainable support for agriculture, and constantly improve the coverage of financial services in rural areas. Second, accelerate the development of various forms of new rural financial organizations and regional small- and medium-sized banks mainly serving rural areas, and vigorously develop microfinance and microfinance services. At the same time, small rural financial organizations are allowed to integrate funds from formal financial institutions. Third, we should further improve the legal system of rural finance, standardize the nongovernmental financial behavior, absorb social capital and nongovernmental funds, and meet the needs of rural economic development.

(2) Standardize rural financial consumer products to meet the multilevel consumption needs of rural areas. There are not only differences in urban and rural financial consumption, but also different levels of consumption. Urban financial services can provide housing, vehicles, and personal consumption loans for urban residents, while rural finance is very weak in this aspect. To standardize rural financial consumer products, it is necessary to introduce a third-party evaluation agency to evaluate the risk of rural financial consumer products. When promoting financial products, we should follow the principle of risk matching, prohibit promoting or misleading rural financial consumers to buy financial products that are inconsistent with their risk tolerance, and effectively protect the rights and interests of financial consumers. In order to meet the diversified needs of rural residents for financial consumer products, rural financial institutions can combine the actual situation of local rural areas to launch simple and practical financial consumer products.

(3) With the development of rural economy and the acceleration of the process of urban-rural integration, the financial service needs of rural residents are increasingly diversified and specialized. To improve the rural financial consumption system and expand the rural financial consumption market, we should relax the market access conditions and encourage the emergence and growth of various types of financial consumption, especially the development of durable consumer goods credit. Second, we should make full use of the opportunity of "finance going to the countryside," actively carry out the propaganda of financial consumption knowledge, enhance the financial consumption awareness of rural residents, update the traditional consumption concept, and transform the potential consumption awareness into the actual consumption behavior. Third, we should tap the market potential and broaden the field of financial consumption services. Financial institutions should establish the overall concept and development concept and extend the field of financial consumption services from the city to the vast rural areas so that the vast number of rural residents can enjoy equal financial consumption services with urban residents. Fourth, we should improve the management of financial consumption, introduce financial support and guarantee mechanisms, and 
give financial assistance to specific types of financial consumption.

\section{Consumers}

(1) We will improve the laws related to the protection of financial consumers' rights and interests. First, improve the relevant laws, further clarify the rights and obligations of financial consumers and financial institutions, and introduce measures related to the rights and interests of rural financial consumers. Second, put consumers' rights and interests into the regulatory objectives, and establish the legal status of financial regulators in the protection of financial consumers' rights and interests. Third, to further improve the information disclosure system, it is necessary for financial institutions to comprehensively, accurately, and timely disclose their product and service information.

(2) Establish financial consumer protection institutions. First, strengthen coordination of rights protection. Set up special financial consumer protection institutions in the regulatory department and corresponding organizations in the financial industry association. Through multilevel organizations, it plays an active role in rural financial consumer education, consumer risk warning, and handling financial consumer complaints. Second, strengthen the education of safeguarding rights. It is necessary for regulatory authorities, industry associations, and financial institutions to actively carry out various forms of financial knowledge publicity and education for rural financial consumers. While enriching the financial knowledge of rural consumer groups, we should further improve the legal awareness of rural financial consumers.

(3) Improve the financial consumer complaints platform. The protection and maintenance of the rights and interests of rural financial consumers need an appropriate complaint and handling platform. First, set up a special department for handling consumer complaints. Establish a consumer complaint database; classify, investigate, and mediate in consumer complaints; and regularly analyze information to identify potential problems, to provide a reference for the formulation of relevant laws and regulations. Second, establish consumer self-discipline organizations in the banking industry to coordinate disputes. Third, improve the compensation and punishment system. Give consumers the right to recover from financial institutions after the event, and improve the compensation to consumers and the punishment to financial institutions.

\section{Conclusion}

This paper introduces the CGE model, uses the fuzzy clustering algorithm of univariate evolution, obtains the fuzzy analogy function of individual consumers in the rural financial market, and combines them with the improved AHP method to analyze the relationship between rural customers' perception of financial service quality, customer satisfaction, and customer trust, to determine the superiority of the trust mechanism of individual consumers in the rural financial market. The dynamic analysis of the trust mechanism of individual consumers in the rural financial market provides new ideas for the steady development of rural financial consumer market.

\section{Future Research Directions}

(1) In this paper, the elements of the consumer trustbuilding mechanism need to be refined and supplemented. For example, when consumers purchase products, the calculation of the benefits brought by the products they choose and the risks brought by the failure of choice should also belong to a new mechanism. In this way, the study of consumer trust mechanisms will be more perfect.

(2) The consumer trust mechanism studied in this paper is based on the research background of China's home appliance industry, but in fact many industries similar to the home appliance industry have great similarities. The process and conclusion of this study, to a certain extent, are also applicable to these industries. Based on the research method of this paper, it is feasible to study the consumer trust mechanism of other similar industries.

\section{Data Availability}

The data used to support the findings of this study are available from the corresponding author upon request.

\section{Conflicts of Interest}

The authors declare that they have no conflicts of interest.

\section{Acknowledgments}

This work was supported by the Education and Scientific Research Project of Young and Middle-Aged Teachers of Fujian Department of Education (Social Science) (Grant no. JAS19578).

\section{References}

[1] R. Sousa, C. Horta, R. Ribeiro, and E. Rabinovich, "How to serve online consumers in rural markets: e," Business Horizons, vol. 63, no. 3, pp. 351-362, 2020.

[2] L. Yan, K. Hong, K. Chen, H. Li, and L. Liao, "Benefit distribution of collectively-owned operating construction land entering the market in rural China: a multiple principal-agent theory-based analysis," Habitat International, vol. 109, no. 2, Article ID 102328, 2021.

[3] T. Potocki and M. Cierpiał-Wolan, "Factors shaping the financial capability of low-income consumers from rural regions of Poland," International Journal of Consumer Studies, vol. 43, no. 2, pp. 187-198, 2019. 
[4] E. Krivosheya, "The role of financial innovations in consumer behavior in the Russian retail payments market," Technological Forecasting and Social Change, vol. 161, no. 7, Article ID 120304, 2020.

[5] X. Li, X. Yao, Z. Guo, and J. Li, "Employing the CGE model to analyze the impact of carbon tax revenue recycling schemes on employment in coal resource-based areas: evidence from Shanxi," The Science of the Total Environment, vol. 720, no. 10, Article ID 137192, 2020.

[6] L. J. Brown, G. M. Jones, and M. J. Bond, "E.-health: Psychosocial challenges for South Australian rural mental health consumers," Rural and Remote Health, vol. 19, no. 3, pp. 174-184, 2019.

[7] M. R. Mohapatra, N. S. Moirangthem, and P. Vishwakarma, "Mobile banking adoption among rural consumers: evidence from India," American Business Review, vol. 23, no. 2, pp. 300-315, 2020.

[8] X. Cui, J. J. Xiao, and J. Yi, "Employment type, residential status and consumer financial capability: evidence from China household finance survey," Singapore Economic Review, vol. 64, no. 1, pp. 57-81, 2019.

[9] K. Mahasuar and S. Patnaik, "Strategic innovations in distribution channels - an emerging market perspective and case studies from consumer packaged goods (CPG) industry of India," Strategic Direction, vol. 35, no. 1, pp. 13-16, 2019.

[10] B. Rokicki, E. A. Haddad, J. M. Horridge, and M. Stpniak, "Accessibility in the regional CGE framework: the effects of major transport infrastructure investments in Poland," Transportation, vol. 26, no. 48, pp. 747-772, 2020.

[11] P. Qin, P. Chen, X.-B. Zhang, and L. Xie, "Coal taxation reform in China and its distributional effects on residential consumers," Energy Policy, vol. 139, no. 15, Article ID 111366, 2020.

[12] I. Opitz, F. Zoll, I. Zasada, A. Doernberg, R. Siebert, and A. Piorr, "Consumer-producer interactions in communitysupported agriculture and their relevance for economic stability of the farm - an empirical study using an Analytic Hierarchy Process," Journal of Rural Studies, vol. 68, no. 5, pp. 22-32, 2019.

[13] Y. Weng, S. Chang, W. Cai, and C. Wang, "Exploring the impacts of biofuel expansion on land use change and food security based on a land explicit CGE model: a case study of China," Applied Energy, vol. 236, pp. 514-525, 2019.

[14] R. Langarita, R. Duarte, G. Hewings, and J. Sánchez-Chóliz, "Testing European goals for the Spanish electricity system using a disaggregated CGE model," Energy, vol. 179, pp. 1288-1301, 2019.

[15] B. Lin and Z. Jia, "Economic, energy and environmental impact of coal-to-electricity policy in China: a dynamic recursive CGE study," The Science of the Total Environment, vol. 698, no. 1, Article ID 134241, 2019. 